\title{
Taking off my running shoes: a 'tutorial' in chronic osteoarthritis
}

I impatiently bounded up six flights of steps without needing to catch my breath. Long distance running has its benefits. Strong legs and a confident stride; be it grassy plains, concrete pavements, or stairs leading up to a council flat in central London. I rang the doorbell and waited for Mrs BM to shuffle up to the door. I quickly introduced myself, the fifth year medical student working with her GP, and she invited me into the lounge.

She began to patiently explain the impact of back pain on her life. It comes on when she stands for too long. She must take frequent breaks, sitting or lying down, to relieve the pain. The dishwasher and washing machine have made a big difference to her. The pain also stops her from ironing and bending over to pick things up.

Heavy chores like vacuuming are out of the question. She lives with her son who takes care of those chores on the weekend. Every week her daughter helps her out with grocery shopping. While Mrs BM appreciates help from her children, she is loath to let social services into the house. 'I don't want to be hanging around waiting for them, tied down and not free.'

'I like my independence and to be free to do what I want', she says. She can only cross the road from her flat before her back pain becomes intolerable. However, using her three-wheeled walker, she can go as far as she wants, 'I can fly with that!' I recognised that lilt in her voice; I am just as excited when I lace up my running shoes. But unlike a wheeled walker, my running shoes do not stop me boarding buses or climbing stairs. She explains, 'I ring them immediately if the lift is broken. I say that if it isn't fixed, I'm housebound'.

Mrs BM barely used the wheeled walker until she had a fall 18 months ago. She had another fall in June when she tripped over the telephone cord. I wondered how she coped mentally. She explained, 'I don't let it affect me too much, if you do, you might as well die. You just have to get on with it.
I accept the fact that it's not going to get better. I'm 88. You can't expect things to be as they are when you're 28 can you?' That happens to be what I hope for; I am 24 and I find it hard to imagine the condition of my body 64 years later.

The pain is gradually getting worse since her diagnosis 10 years ago. But she chooses not to complain, 'I would never inflict others with it. What can they do?' Her son echoes the sentiment, 'we don't know how we can help you'. Mrs BM says, 'I'm very lucky, I have a very good family.' She appreciates her daughter accompanying her to hospital appointments and she always looks forward to visiting her eldest son in America. Her Catholic faith also helps her cope, although she says 'I don't expect to be cured'.

Mrs BM's pain is controlled with paracetamol, tramadol hydrochloride, a transcutaneous electrical nerve stimulator, and corticosteroid injections in her facet joints. Mrs BM declined amitriptyline and pregabalin because she did not want drowsiness to hinder her mobility. She also performs physiotherapy exercises to maintain muscle strength. Although Mrs BM is far from being pain free, she is grateful to her GP: 'he's given me everything'.

'The only problem I have is the arthritis', she says. In fact, she is being treated for congestive heart failure and ischaemic heart disease, as well as osteoporosis. She has also been diagnosed with hiatus hernia and sensorineural hearing loss in both ears. In the past, Mrs BM has been treated for tuberculosis, rosacea, thyrotoxicosis, left bundle branch block, a full thickness rotator cuff tear, and recurrent urinary tract infections.

I am slowly learning that, 'A sick patient does not represent a biochemistry problem, an anatomy problem, a genetics problem, or an immunology problem; rather, each person is the product of myriad molecular, cellular, genetic, environmental, and social influences that interact in complex ways to determine health and disease." In opening up her home and schedule, Mrs BM allowed me a closer look at the impact of chronic disease on a patient's life.

The exercise took time. My aim of moving through life as quickly as I can is reflected in my love of running; to get faster and faster. A friend was only half joking when he chastised me for loving sport more than people. Perhaps it is time to slow down or risk qualifying as a doctor and yet fail to develop compassion, the essence of medicine. ${ }^{2}$ I mentally unlaced my running shoes as I left Mrs BM's flat. Instead of tearing down the stairs, I pressed the call button for the lift. I waited; wiggling my toes in a different pair of 'shoes'.

\section{Hugh Ip}

\section{Consent}

The patient gave her consent for this article to be published.

\section{REFERENCES}

1. Dienstag JL. Becoming a physician: relevance and rigor in premedical education. $N$ Engl J Med 2008; 359: 221-224.

2. Sokol D. The essence of medicine. BMJ 2008; 336 ; 1163.

DOI: 10.3399/bjgp10X484066 